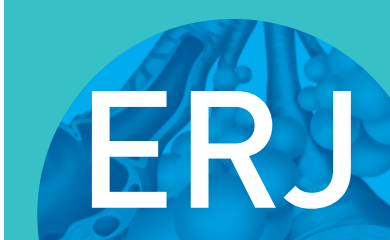

open research

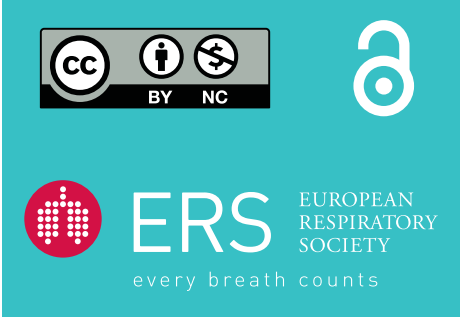

\section{Asthma and body mass definitions affect estimates of association: evidence from a community-based cross-sectional survey}

\section{To the Editor:}

Asthma and obesity have been on the rise for the past few decades, becoming the most prevalent chronic conditions in children $[1,2]$. Obesity has been suggested to increase asthma incidence and prevalence, and change asthma towards a more difficult-to-control phenotype [3]. Yet, the impact of heterogeneous asthma and obesity definitions on the suggested association has been poorly explored. As such, we aimed to evaluate the influence of different asthma and obesity definitions on the obesity-asthma relationship.

Data for this study were collected from a cross sectional analysis of 845 children (50.8\% boys) aged 7-12 years, attending 71 classrooms in 20 public schools located in the city of Porto, Portugal [4]. Briefly, information on symptoms and lifestyle were assessed by questionnaire, and participants had their anthropometry, lung function, airway inflammation and atopic status evaluated.

Weight (in kilograms) and percentage of body fat were measured using a digital scale (BC-418 Segmental Body Analyzer; Tanita, Lisbon, Portugal), and height (in centimetres) was measured with a portable stadiometer. Body mass index (BMI) was calculated at weight $/ \mathrm{height}^{2}$ (in $\mathrm{kg} \cdot \mathrm{m}^{-2}$ ) and classified into different categories (thinness, normal weight, overweight and obesity) according to age- and sex-specific percentiles. According to the US Centers for Disease Control and Prevention (CDC), the BMI of children was defined normal weight, overweight and obese between the fifth and $<85$ th, between the 85 th and $<95$ th, and $\geqslant 95$ th, respectively [5]; following the cut-offs defined by the World Health Organization (WHO), children were determined to be obese, overweight and normal weight for BMI $z$-scores $>2, \leqslant 2$, and between $\geqslant 2$ and $\leqslant 1$, respectively [6]. Based on the International Obesity Task Force (IOTF), each weight category was performed using the cut-off values associated with the percentile curves, namely obesity, overweight and normal weight when they passed through BMI values 30,25 and $18.5 \mathrm{~kg} \cdot \mathrm{m}^{-2}$ at age 18 years, respectively [7]. Percentage of body fat was also classified by age- and sex-specific centile curves for body fat in children, in which cut-offs were set at the second, 85th and 95th centiles to characterise regions of underfat, normal, overfat and obese, respectively [8]. The prevalence of overweight and obesity was $27.3 \%, 34.6 \%, 27.3 \%$ and $15.9 \%$ according to CDC, WHO, IOTF and percentage of body fat, respectively.

Lung function and airway reversibility were assessed by spirometry, and were recorded before and after inhalation of $400 \mu \mathrm{g}$ salbutamol. Positive bronchodilation was defined based on $\geqslant 12 \%$ and $\geqslant 200 \mathrm{~mL}$ increase in forced expiratory volume in $1 \mathrm{~s}$ after bronchodilation. Different asthma definitions were considered as follows. 1) Medical diagnosis: self-reported medical diagnosis; ii) medical diagnosis or positive bronchodilation; 3) medical diagnosis with asthma symptoms, reported symptoms (wheezing, dyspnea or dry cough) occurring in the past 12 months, or positive bronchodilation; and 4) medical diagnosis and under asthma treatment (currently under antiasthma medication). Accordingly, prevalence was $6.5,12.3,10.8$ and $5.3 \%$ for medical diagnosis, medical diagnosis or positive bronchodilation, medical diagnosis with asthma symptoms or positive bronchodilation, and medical diagnosis under asthma treatment, respectively.

@ERSpublications

Differing body mass classifications challenge the strength of the epidemiological evidence suggesting asthma and obesity are linked. The relationship between asthma and overweight in children depends on the body mass definitions adopted. http://bit.ly/2lSxhC5

Cite this article as: de Castro Mendes F, Paciência I, Rufo JC, et al. Asthma and body mass definitions affect estimates of association: evidence from a community-based cross-sectional survey. ERJ Open Res 2019; 5: 00076-2019 [https://doi.org/10.1183/23120541.00076-2019].

Copyright $\odot$ ERS 2019. This article is open access and distributed under the terms of the Creative Commons Attribution NonCommercial Licence 4.0. 
TABLE 1 Association between body mass categories and asthma definitions

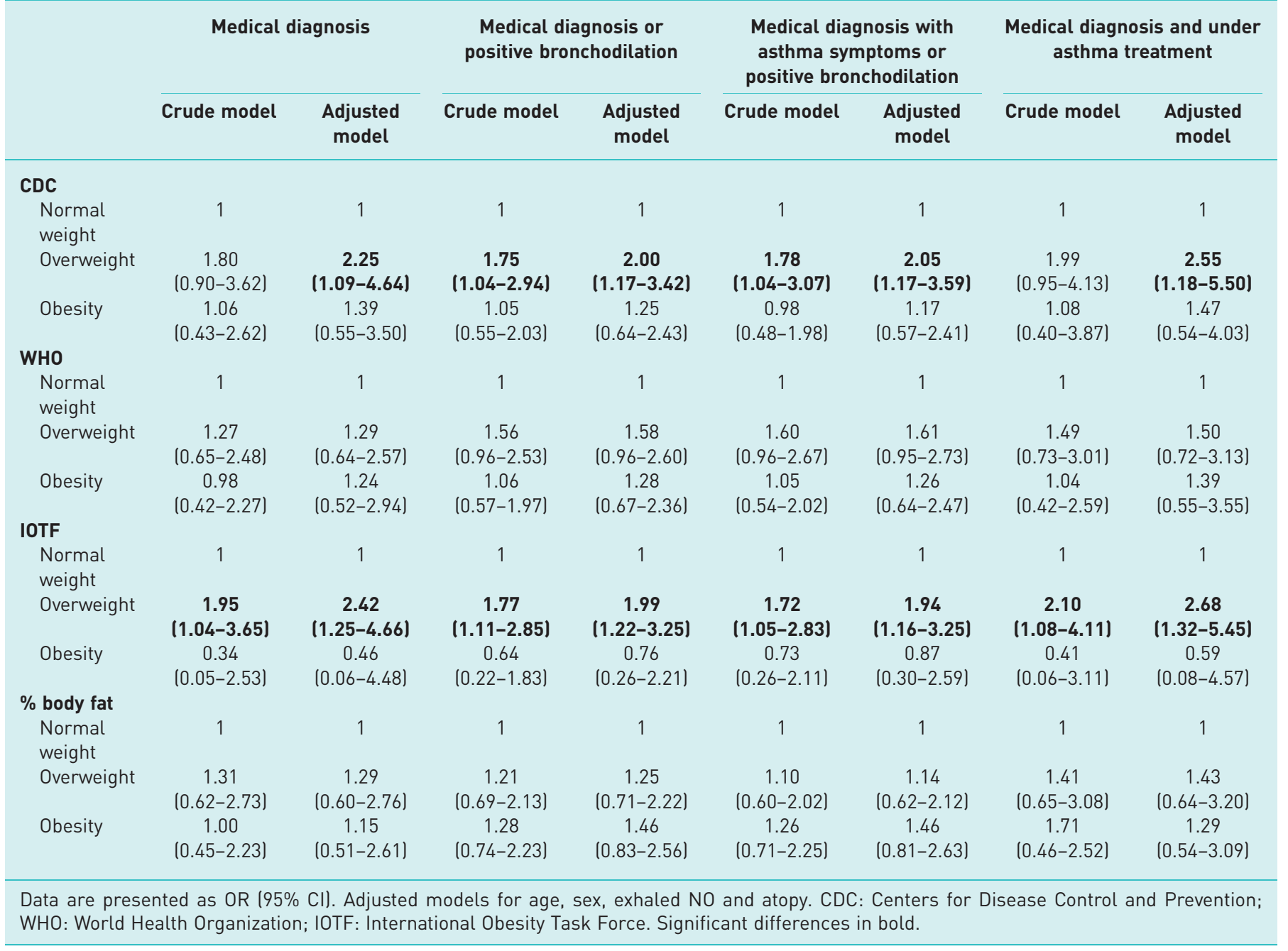

Levels of exhaled nitric oxide were measured to assess airway inflammation using the NObreath analyser (Bedfont Scientific Ltd, Rochester, UK). Skin-prick tests (SPTs) were performed on children's forearms to evaluate allergic sensitisation using a QuickTest (Panatrex Inc., Placentia, CA, USA) applicator, which contained house dust mite, weed pollen, grass pollen mix, cat dander, dog dander, Alternaria alternata, negative control (extract diluent) and a positive control consisting of histamine $10 \mathrm{mg} \cdot \mathrm{mL}^{-1}$ (HAL Allergy, Leiden, the Netherlands). Results were read 15 min afterwards and atopy was defined by a positive SPT to at least one of the allergens.

The SPSS statistical package software version 25.0 (IBM, Armonk, NY, USA) was used to analyse the data statistically. Logistic regression models were performed to determine the association between asthma definitions and body mass categories. The underweight category was not included in this analysis because a limited number of children with asthma were underweight $(n<5)$, preventing the establishment of a good model. Age, sex, exhaled NO and atopy were analysed as potential confounders. Significant differences were reported with an $\alpha$-value inferior to $5 \%(\mathrm{p}<0.05)$. The study was approved by the local ethics committee, procedures were in accordance with Helsinki Declaration and written consent was obtained from the children's legal guardians.

After adjustment, the risk of asthma was significantly higher in overweight children compared with those of normal weight according to CDC and IOTF classifications (table 1). No significant associations were observed between asthma definitions and overweight according to WHO and percentage of body fat, nor with obesity. 
Our results indicate that, independently of the asthma definition adopted, the risk of asthma was significantly higher in children classified as overweight according to CDC and IOTF classifications. Although the risk of asthma suggested a similar tendency with the remaining BMI classifications, our findings support that the relationship between BMI categories and asthma in epidemiological studies in children depends on the definitions adopted, which may increase the controversy over the association and temporal relationship between overweight and asthma in children.

The obese asthma phenotype is complex and multifactorial, as are both obesity and asthma [9]. A possible explanation for the difficulty found when studying this phenotype might be the different asthma definitions and BMI classifications adopted, as we showed in the present study. Accordingly, previous studies showed a different magnitude of agreement coefficients between BMI classifications [10] and regarding childhood asthma; in addition, prevalence estimates varied substantially with the definition adopted [11]. Asthma is an umbrella term applied to a group of conditions characterised by varying degrees of airflow limitation, different patterns of inflammation, contributions from bacterial and viral infections that vary over time, an oversensitive cough reflex, and mucus hypersecretion. It is therefore plausible that different body mass classifications challenge the strength of the epidemiological evidence that suggests asthma and obesity are linked.

In conclusion, discrepancies in the epidemiological literature regarding the strength of the obesity-asthma association in children may be partially explained by the different BMI classifications adopted.

Francisca de Castro Mendes ${ }^{1}$, Inês Paciência $\odot^{1,2,3}$, João Cavaleiro Rufo $\odot^{3}$, Diana Silva ${ }^{1,4}$, Pedro Cunha ${ }^{5}$, Mariana Farraia ${ }^{3}$, Luís Delgado $\oplus^{1,4}$, Pedro Moreira ${ }^{3,5}$ and André Moreira ${ }^{1,3,4,5}$

${ }^{1}$ Serviço de Imunologia Básica e Clínica, Departamento de Patologia, Faculdade de Medicina da Universidade do Porto, Porto, Portugal. ${ }^{2}$ Institute of Science and Innovation in Mechanical Engineering and Industrial Management (INEGI), Porto, Portugal. ${ }^{3}$ EPIUnit - Instituto de Saúde Pública, Universidade do Porto, Porto, Portugal. ${ }^{4}$ Serviço de Imunoalergologia, Centro Hospitalar São João, Porto, Portugal. ${ }^{5}$ Faculdade de Ciências da Nutrição e Alimentação da Universidade do Porto, Porto, Portugal.

Correspondence: Francisca de Castro Mendes, Faculdade de Medicina da Universidade do Porto and Centro Hospitalar São João, Alameda Prof. Hernâni Monteiro, 4200-319 Porto, Portugal. E-mail: francisca_castromendes@hotmail.com

Received: 19 March 2019 | Accepted after revision: 25 Aug 2019

Author contributions: All authors were involved in investigation and gave constructive criticism of the study manuscript. F. de Castro Mendes and A. Moreira wrote the manuscript with input from all authors.

Conflict of interest: None declared.

Support statement: Authors gratefully acknowledge the funding by the project NORTE-01-0145- FEDER-000010 Health, Comfort and Energy in the Built Environment (HEBE), cofinanced by Programa Operacional Regional do Norte (NORTE2020), through Fundo Europeu de Desenvolvimento Regional (FEDER) and EXALAR 21 funded by the European Regional Development Fund (FEDER), through the Competitiveness and Internationalization Operational Programme, and by national funding from the Foundation for Science and Technology (FCT) under the scope of the project PTDC/GES-AMB/30193/2017 (POCI-01-0145-FEDER-030193, 02/SAICT/2017 - project number 30193). Funding information for this article has been deposited with the Crossref Funder Registry.

\section{References}

1 Chastang J, Baiz N, Parnet L, et al. Changes in body mass index during childhood and risk of various asthma phenotypes: a retrospective analysis. Pediatr Allergy Immunol 2017; 28: 273-279.

2 den Dekker HT, Ros KPI, de Jongste JC, et al. Body fat mass distribution and interrupter resistance, fractional exhaled nitric oxide, and asthma at school-age. J Allergy Clin Immunol 2017; 139: 810-818.

3 Moreira A, Bonini M, Garcia-Larsen V, et al. Weight loss interventions in asthma: EAACI evidence-based clinical practice guideline (part I). Allergy 2013; 68: 425-439.

4 Paciencia I, Cavaleiro Rufo J, Silva D, et al. Exposure to indoor endocrine-disrupting chemicals and childhood asthma and obesity. Allergy 2019; 74: 1277-1291.

5 Kuczmarski RJ, Ogden CL, Grummer-Strawn LM, et al. CDC growth charts: United States. Adv Data 2000; 314: $1-27$.

6 de Onis M, Onyango AW, Borghi E, et al. Development of a WHO growth reference for school-aged children and adolescents. Bull World Health Organ 2007; 85: 660-667.

7 Cole TJ, Lobstein T. Extended international (IOTF) body mass index cut-offs for thinness, overweight and obesity. Pediatr Obes 2012; 7: 284-294.

8 McCarthy HD, Cole TJ, Fry T, et al. Body fat reference curves for children. Int J Obes (Lond) 2006; 30: 598-602.

9 Forno E. Childhood obesity and asthma: to BMI or not to BMI? J Allergy Clin Immunol 2017; 139: 767-768. 
10 Kêkê LM, Samouda H, Jacobs J, et al. Body mass index and childhood obesity classification systems: a comparison of the French, International Obesity Task Force (IOTF) and World Health Organization (WHO) references. Rev Epidemiol Sante Publique 2015; 63: 173-182.

11 Van Wonderen KE, Van Der Mark LB, Mohrs J, et al. Different definitions in childhood asthma: how dependable is the dependent variable? Eur Respir J 2010; 36: 48-56. 